\title{
PEMBUDAYAAN DEMOKRASI DI PESANTREN DALAM MENGEMBANGKAN CIVIC DISPOSITION SANTRI
}

\author{
Supangat, Muhammad Halimi \\ Program Studi Pendidikan Kewarganegaraan Universitas Pendidikan Indonesia \\ Jl. Setiabudhi N0.229 Isola Sukasari Bandung \\ email: supangat@ student.upi.edu
}

\begin{abstract}
This article is motivated by issues attitude and character of citizenship among the younger generation which is very alarming. The understanding of democracy that one result of excessive democratic freedoms. Disorientation attitude and character citizenship (civic disposition) experienced by almost all elements of the nation thus eliminating the identity of the nation and much of the value-milai democracy. Pesantren Daarut Tauhid as modern schools also provide planting of democratic values among his students. The data were taken with the study documentation, observations, interviews, and the active participation of researchers in the field. The results of this study found: democracy education should be introduced in educational institutions schools, for boarding institutions are educational institutions which make the process of developing the potential of learners (students). Through the process of democratic education will produce a democratic man.For students develop civic disposition, pendidikkan process conducted in schools in various ways; 1 ) exemplary; 2) exercise and habituation; 3) educate through ibrah (taking lessons); 4) educate through mauidzah (advice); 5) educate through discipline; and 6) educate targib wa tahzid (inducements and threats).
\end{abstract}

Keyword: civilizing democracy, islamic school, civic disposition santri

\begin{abstract}
Abstrak: Artikel ini dilatarbelakangi oleh persoalan sikap dan watak kewarganegaran di kalangan generasi muda yang sangat memprihatinkan. Pemahaman terhadap demokrasi yang salah mengakibatkan kebebasan berdemokrasi yang kebablasan. Disorientasi sikap dan watak kewarganegaraan (civic disposition) hampir dialami oleh seluruh elemen bangsa sehingga menghilangkan jati diri anak bangsa dan jauh dari nilai-milai demokrasi. Pesantren Daarut Tauhid sebagai pesantren modern juga memberikan penanaman nilai-nilai demokrasi dikalangan para santrinya. Data dalam penelitian ini diambil dengan studi dokumentasi, observasi, wawancara, dan partisipasi aktif peneliti dilapangan. Hasil dari penelitian ini ditemukan: Pendidikan demokrasi hendaknya dikenalkan di lembaga pendidikan pesantren, karena lembaga pesantren merupakan lembaga pendidikan yang melakukan proses mengembangkan potensi peserta didik (santri). Melalui proses pendidikan demokrasi akan menghasilkan manusia yang demokratis.Untuk mengembangkan civic disposition santri, proses pendidikkan yang dilakukan di pesantren dengan berbagai cara yaitu; 1 ) keteladanan; 2) latihan dan pembiasaan; 3) mendidik melalui ibrah (mengambil pelajaran); 4) mendidik melalui mauidzah (nasehat); 5) mendidik melalui disiplin; dan 6) mendidik targib wa tahzid (bujukan dan ancaman).
\end{abstract}

Kata kunci : pembudayaan demokrasi, pesantren, civic disposition santri

Wilayah Indonesia yang terbentang dari Sabang sampai Merauke memiliki potensi keberagaman dan kemajemukan masyarakat yang sangat besar, hal ini menjadi tantangan tersendiri bagi bangsa Indonesia. Terutama dalam hal memberdayakan kemajemukan masyarakat, suku, etnik, agama, bahasa, budaya, kelompok sosial.
Pemberdayaan keberagaman dan kemajemukan masyarakat tersebut tidak terlepas dari peran serta pemuda sebagai generasi penerus bangsa. Keterlibatan generasi muda khususnya kaum santri dalam menanamkan nilai-nilai demokrasi di Pesantren juga banyak memberikan pengaruh yang besar. Lingkungan pesantren memiliki 
kekhasan tersendiri dalam mengelola keberagaman dan kemajemukan yang ada. Dalam penyelenggaraan pendidikan di pesantren, Kyai mempunyai peranan yang sangat strategis dalam menentukan kebijakan-kebijakan pesantren. Dengan demikian lembaga pendidikan pesantren seyogyanya juga dapat menjadi media strategis dalam menerapkan Pendidikan Demokrasi, karena lembaga pesantren merupakan suatu lembaga pendidikan yang bertumpu pada proses mengembangkan potensi peserta didik (santri) yang notabene adalah warga negara.

Mereka adalah penerus cita-cita bangsa dan merupakan sumber insan bagi pembangunan Nasional. Melalui proses pendidikan demokrasi dapat menghasilkan manusia yang demokratis yang memiliki kesadaran dan keyakinan bahwa masyarakat demokratis dapat memaksimalkan kesejahteraan dan kebebasan secara baik dan benar. Hal ini sesuai dengan yang dikemukakkan oleh Zamroni (2011: 39) bahwa pendidikan harus mampu melahirkan manusia-manusia yang demokratis. Tanpa manusia-manusia yang memegang teguh nilai-nilai demokrasi, masyarakat yang demokratis hanya akan merupakan impian belaka. Kehidupan masyarakat yang demokratis harus didasarkan pada kesadaran warga bangsa atas ide dan cita-cita demokrasi yang melahirkan kesadaran dan keyakinan bahwa hanya dalam masyarakat demokratislah dimungkinkan warga bangsa untuk memaksimalkan kesejahteraan dan kebebasan.

Istilah demokrasi sendiri sebagai paham kebebasan yang mendunia, telah merambah ke berbagai pelosok lapisan kehidupan masyarakat namun tidak cukup banyak dipahami secara matang. Dari keterbatasan pemahaman dan pengetahuan tentang demokrasi tersebut, ditambah adanya perbedaan persepsi yang mendasar tentang demokrasi dalam mengimplementasikan, sehingga demokrasi sering disalah artikan. Untuk menyikapi hal ini maka perlunya sebuah kedewasaan dan kematangan dalam mengimlementasikan nilai-nilai budaya demokrasi. Sundawa (2011), berpendapat "ketidak matangan, ketidak dewasaan, dan ketidak arifan warga negara dalam mengimplementasikan demokrasi tidak terlepas dari kurang berhasilnya penanaman nilai-nilai demokrasi dalam dunia pendidikan".

Demokrasi juga merupakan sebuah proses, dimana dalam pembelajaran demokrasi dibutuhkan proses yang teliti dan cermat guna terwujudnya demokrasi yang genuine (asli). Hal ini sejalan dengan pendapat Darmawan (2015:96-97) yang menyatakan bahwa demokrasi itu adalah sebuah proses dan dalam prosesnya bukanlah milik penguasa melainkan milik rakyat karena rakyat merupakan ruh dari kehidupan demokrasi itu sendiri. Sehingga upaya demokratisasi dianggap sebagai pembelajaran demokrasi yang berorientasi kepada ideologi bangsa yaitu Pancasila, karena menurut Darmawan bahwa demokrasi itu tergantung pada ideologi suatu bangsa.

Pembudayaan demokrasi yang sering dikenal dengan istilah proses demokratisasi, dipahami sebagai kondisi dimana di dalam prosesnya dibutuhkan media sebagai pendukung proses tersebut. Dalam pembudayaan demokrasi atau disebut pendidikan demokrasi, media sangat berperan penting khususnya bagi seorang pendidik. Nilai-nilai demokrasi dan civic disposition sangat berkaitan erat. Winataputra dan Budimansyah (2007:61) mengemukakan bahwa yang dimaksud dengan civic disposition adalah kepribadian yang mencakup kesopanan dan interaksi manusiawi, tanggung jawab individual, disiplin diri, kepedulian terhadap masyarakat, keterbukaan pikiran yang mencakup keterbukaan, skeptisisme pengenalan terhadap kemenduaan, sikap kompromi yang mencakup prinsip-prinsip konflik dan batas-batas kompromi, toleransi pada keragaman, kesabaran dan keajegan, keharuan, kemurahan hati, dan kesetian terhadap bangsa dan segala prinsipnya.

Dalam mengembangkan civic disposition santri yang ungggul, mandiri, pesantren memiliki tujuan tersendiri. Sebagai mana tujuan pendidikan pesantren seperti yang dikemukakan oleh Mastuhu (2007) yaitu Menciptakan dan mengembangkan kepribadian muslim, yaitu kepribadian muslim yang beriman dan bertakwa kepada Tuhan, berakhlak mulia, bermanfaat dan berkhidmat kepada masyarakat, mampu berdiri sendiri, bebas dan teguh dalam kepribadian, menyebarkan agama dan menegakkan Islam dan kejayaan umat, mencintai ilmu dalam rangka mengembangkan kepribadian Indonesia. Dari tujuan pesantren, dipahami bahwa pengembangan civic disposition sangat dibutuhkan santri, sehingga dengan demikian santri akan memiliki nilai lebih bila dibandingkan dengan siswa disekolah pada umumnya. Hal ini bisa kita lihat dari keteraturan dan kedisiplinan pesantren dalam mengkondisikan santrinya. Selain itu santri akan terjaga dan dapat menerapkan nilai-nilai 
demokratis secara baik di lingkunagan pesantren dan masyarakat. Hal inilah yang menjadi pembeda antara pesantren dan sekolah formal. Dhofier (1982), berpendapat "pesantren merupakan salah satu "benteng moral bangsa dan indigenous Indonesia".

Pesantren sebagai lembaga pendidikan sangat diharapkanperan sertanya dalam menumbuhkan dan membudayakan nilai-nilai demokrasi. Sehingga pemahaman nilai-nilai demokrasi kepada santri melalui pengembangan civic disposition santri, mampu menghadapi realitas sosial dalam kehidupan. Penanaman nilainilai demokrasi ini dilakukan dalam rangka membina santri agar mereka tidak tercabut dari akar budaya demokrasi yang seutuhnya ketika mereka berhadapan dengan realitas sosial budaya diera globalisasi. Untuk mengembangkan civic disposition santri,proses pendidikkan yang dilakukan di pesantren dengan berbagai cara yaitu: (1) keteladanan; (2) latihan dan pembiasaan; (3) mendidik melalui ibrah (mengambil pelajaran); (4) mendidik melalui mauidzah (nasehat); (5) mendidik melalui disiplin; dan (6) mendidik targib wa tahzid (bujukan dan ancaman).

Pembentukan warga negara yang Demokratis sebagai unsur pengembangan kompetensi Civic Disposition. Sehubung dengan itu, Winataputra dan Budimansyah (2012:234235), menjelaskan bahwa Civic Education memiliki paradigma dasar yaitu Civic Culture. Sedangkan Civic Culture memiliki ketergantungan dan saling ketergantungan (interdependence) dengan political culture. Kemudian Civic Culture sendiri menjadi pengembang dari elemen penting civic education yaitu civic virtue dan civic virtue sendiri berkaitan dengan domain psikososial individu yang secara substantif mengembangkan unsur civic disposition dan civic committments. Hal inilah yang diperlukan untuk kebiasaan berpikir warga negara demi berkembangnya fungsi sosial yang sehat dan jaminan kepentingan umum dari sistem demokrasi.

Jadi dapat dipahami bahwa civic education berhubungan erat dengan pendidikan demokrasi yang bertujuan untuk mengembangkan $\mathrm{Civic} C \mathrm{Cul}$ ture dan dengan Civic Culture tumbuhlah elemen civic disposition dan civic committments pada warga negara. Dengan civic dispositions dan civic committments tersebut diyakini dapat melahirkan the common good atau terwujudnya kemaslahatan kepentingan umum. Hal diatas tentunya sejalan dengan apa yang dirangkum oleh Winataputra dan Budimansyah (2012:234-235) yakni elemen civic culture yang paling sentral dan sangat perlu dikembangkan adalah civic virtue. Civic virtue yang dimaksud adalah kemauan warganegara untuk menempatkan kepentingan umum di atas kepentingan pribadi. Civic virtue sendiri secara substantif memiliki dua unsur yaitu unsur civic dispositions dan civic committments. Civic dispositions yang dimaksud adalah sikap dan kebiasaan berfikir warganegara yang menopang berkembangnya fungsi sosial yang sehat dan jaminan kepentingan umum dari sistem demokrasi. Sementara civic committments yang dimaksud adalah komitmen warganegara yang bernalar dan diterima dengan sadar terhadap nilai dan prinsip demokrasi konstitusional.

\section{METODE}

Metode yang digunakan dalam kajian ini adalah deskriptif analitis. Rasional dari dipilihnya metode deskriptif dalam kajian adalah agar memudahkan dalam menganalisis, mengkaji, dan mengungkapkan informasi argumentatif dan teoritik terkait pembudayaan demokrasi di pesantren dalam mengembangkan civic disposition santri. Dengan menggunakan metode deskriptif, dapat diperoleh gambaran terkait pembudayaan demokrasi di pesantren dalam mengembangkan civic disposition santri secara lebih mendalam. Sukmadinata (2006:72) menyatakan bahwa; metode deskriptif adalah suatu metode dalam meneliti status sekelompok manusia, suatu objek, suatu kondisi, suatu sistem pemikiran atau sesuatu pada masa sekarang. Tujuan dari penelitian deskriptif ini adalah untuk membuat deskripsi akurat mengenai fakta-fakta, sifat-sifat serta hubungan antar fenomena yang terjadi.

Kajian yang ada ini dilakukan di Pesantren Daarut Tauhid Bandung yang berlokasi di Jalan Gegerkalong Girang No.38, Kelurahan Isola, Kecamatan Sukasari, Kota Bandung, Jawa Barat 40154, Telepon. (022) 2005271.Penelitian dilakukan pada semester genap tahun pelajaran 2016/2017 pada bulan Maret 2017 sampai dengan bulan Mei 2017. Artinya penelitian dilakukan dalam selama 3 (tiga) bulan. Teknik pengumpulan data yang ada dilakukan melalui observasi, studi dokumentasi, studi lapangan, dan juga wawancara. Analisis data kualitatif selama dilapangan 
berdasarkan model Miles dan Huberman dalam Sugiyono (2010:337) terdiri atas tiga aktivitas, yaitu data reduction, data display dan conslusion drawing/verification. Adapun teknik analisis data yang diterapkan antara lain Reduksi Data (Data Reduction), Penyajian Data (Data Display), Triangulasi, dan Penarikan Kesimpulan atau Verifikasi.

\section{HASIL DAN PEMBAHASAN}

\section{Pembudayaan demokrasi di Pesantren Daarut Tauhid Bandung}

Pesantren Daarut Tauhid adalah salah satu fenomena pesantren maju di Indonesia. Pesantren Daarut Tauhid mengusung konsep Pesantren Virtual. Santri yang belajar di Pesantren Daarut Tauhid tidak tinggal dalam asrama khusus, melainkan tinggal di pemukiman masyarakat sekitar. Sejarah Pesantren Daarut Tauhid (DT) berawal dari kiprah seorang pemuda Sunda yang bernama Yan Gymnastiar (yang populer dengan panggilan Aa' Gym), beliau diberi nama oleh seorang Imam di Tanah suci Mekkah Abdullah Gymnastiar. Awalnya beliau merintis wadah wiraswasta dengan singkatan KMIW,(Kelompok Mahasiswa Islam Wiraswasta). Aa' Gym menimbah ilmu diberbagai pesantren di Jawa Barat diantaranya di Pondok Pesantren Al-Jauhari Garutyang di pimpin olehKH. Djunaedi, dan di Pondok Pesantren Miftahul Huda Tasikmalaya yang dipimpin oleh KH. Khoer Affandi.

Semakin banyaknya jama' ah yang datang ke pengajian rutin asuhan $\mathrm{Aa}$ ' Gym, sehingga rumah beliau tidak mampu menampung jamaah lagi. Untuk memfasilitasi jamah tersebut, maka pada Tanggal 04 September 1990 didirikanYayasan Daarut Tauhid (DT) yang beralamat di Jalan Gegerkalong Girang No.38, Kelurahan Isola, Kecamatan Sukasari, Kota Bandung, Jawa Barat 40154, dengan Akta Notaris Wiratni Ahmadi, SH. Pada tanggal 7 Desember 1997 dibuka lembaga Pusat Pendidikan dan Pelatihan DT (PUSDIKLAT-DT). Programnya adalah kerjasama pendidikan dan pelatihan Managemen Qolbu (MQ) untuk para eksekutif, staff dan karyawan berbagai perusahaan swasta. Perusahaaan yang mengikuti pelatihan MQ ini adalah Bank Muamalat Indonesia Cabang Bandung, PT Telkom Divre III Jabar, PT Telkom Corporate Office, PT Kereta Api Indonesia
(KAI), Bank Indonesia, Bank Bukopin, PLN Persero dan perusahaan lainnya.

Daarut Tauhid sangat memperioritaskan dakwah di kalangan remaja, karena sebagai tunas-tunas bangsa mereka juga harus diberi bekal kekuatan Ruhiyah lebih dini untuk bisa survive, bahkan muncul sebagai generasi "Winner" (pemenang) dalam menghadapi tantangan zaman di era global yang kian berat. Aneka pembinaan dibuat, seperti; Santri Siap Guna (SSG), Keluarga Mahasiswa Daarut Tauhid (GAMADA), Sanlat (pesantren kilat) Remaja, Pesantren Quantum, Santri Infantri, Santri NAFZA, Forum Silaturahmi Manajemen Qolbu (FSMQ). Semua kegiatan ini diharapkan dapat menjadi "changer" keimanan bagi generasi muda (santri) khususnya dan masyarakat umumnya. Kegiatan-kegiatan Daarut Tauhid menekankan pada aktivitas untuk mewujudkan ajaran Islam yang "membumi” yang tidak sekadar teori namun justru lebih ditekankan pada bukti dan karya nyata. Dengan ini diharapkan keindahan ajaran Islam, etos kerja Islami, Manajemen Islami, Profesionalisme Islami dan solusi Islami atas aneka permasalahan aktual umat dalam kehidupan nyata bisa dirasakan.

DT sebagai pesantren virtual berusaha untuk menjadi pesantren yang tidak memiliki batas dengan masyarakat sekitarnya, berusaha menjadi bengkel akhlak bagi generasi pemuda, programprogram kegiatan yang dilaksanakan dimedia TV (Ceramah Aa' Gym), Radio Ummat 1026 AM dan PT Radio Bening Hati 102,65 MQ FM, Tabloid MQ, Korcil, Jang MQ, Info DT, Pengajianpengajian Aa' Gym dan Teh Ninih dan lain-lain. Semoga Allah meridhai. Sementara aktivitas Pesantren Daarut Tauhid lebih menekankan pengembangan dan perwujudan Islam secara riil, langsung dilaksanakan pada kehidupan sehari-hari bukan sekedar teori. Aktivitas yang dikembangkan menerapkan hubungan dengan Allah (Hablumminallah), dan hubungan dengan manusia dan lingkungan (Hablumminannas), yang diimplementasikan dalam bentuk kegiatan pendidikan dan pelatihan, kegiatan sosial, dan kegiatan bisnis ekonomi. Di usianya yang sudah mencapai 26 tahun (1990-2016), Pesantren Daarut Tauhid ikut serta berkonstribusi dalam mengembangkan kawasan sekitarnya, baik dari SDM, lingkungan masyarakat, maupun ekonomi.

Pembudayaan demokrasi yang dilakukan di lingkungan Pesantren Daarut Tauhid dalam pelaksanaannya mengaplikasikan nilai-nilai budaya 
yang Islami. Budaya yang memadukan nilai-nilai keislaman dengan kondisi masyarakat sekitar pesantren sehingga nilai-nilai yang ditonjolkan di Pesantren Daarut Tauhid seperti budaya disiplin, budaya teratur, budaya bersih, budaya kekeluargaan, dan budaya hormat menghormati antara warga pesantren.

Sikap hormat menghormati yang telah menjadi budaya pesantren berjutuan untuk menjaga keharmonisan hubungan santri, jamaah, dan warga sekitar pesantren. Dari segi pelaksanaan program pesantren, pesantren selalu melibatkan masyarakat yang ada disekitar pesantren, tidak didominasi oleh pengurus pesantren. Sehingga hal ini menciptakan budaya kekeluargaan yang ditumbuhkan oleh pesantren.Karna proses pendidikan demokrasi dapat menghasilkan manusia yang demokratis yang memiliki kesadaran dan keyakinan bahwa masyarakat demokratis dapat memaksimalkan kesejahteraan dan kebebasan secara baik dan benar. Hal ini sesuai dengan yang dikemukakkan oleh Zamroni, (2011: 39) yang menyatakan bahwa pendidikan harus mampu melahirkan manusiamanusia yang demokratis. Tanpa manusiamanusia yang memegang teguh nilai-nilai demokrasi, masyarakat yang demokratis hanya akan merupakan impian belaka. Kehidupan masyarakat yang demokratis harus didasarkan pada kesadaran warga bangsa atas ide dan citacita demokrasi yang melahirkan kesadaran dan keyakinan bahwa hanya dalam masyarakat demokratislah dimungkinkan warga bangsa untuk memaksimalkan kesejahteraan dan kebebasan.

\section{Nilai-nilai Budaya Demokrasi yang dikembangkan di Pesantren Daarut Tauhid Bandung}

Nilai-nilai budaya demokrasi yang dikembangkan di Pesantren Daarut Tauhid yaitu budaya menempatkan sesuatu pada tempatnya, budaya menghormati orang lain, dan budaya disiplin, serta budaya kebersamaan dan keluargaan. Dalam segi pelaksanaan program pesantren, pesantren selalu berusaha untuk melibatkan masyarakat yang ada disekitar pesantren, dalam artian pesantren tidak mendominasi dalam pelaksanaan program pesantren. Sehingga dari kegiatan-kegiatan ini menumbuhkan budaya kekeluargaan, budaya sopan santun, budaya hormat menghormati dan budaya harga menghargai yang diplopori oleh pesantren. Nilai-nilai demokrasi ini tumbuh dan berkembang di lingkungan pesantren tidak ada pemaksaaan dalam pelaksanaanya.

Bahwa nilai-nilai budaya demokrasi di pesantren dapat dilihat dalam pelaksanaan pemilihan ketua angkatan santri yang sedang menimba ilmu di Pesantren Daarut Tauhid, adanya kelompok-kelompok diskusi, musyawarah antara santri dan pembina santri, dan adanya hubungan yang harmonis antara pengasuh pesantren dengan para santri. Pesantren merupakan lembaga pendidikan yang berbasis agama sangat perlu memberikan kiprahnya untuk pembangunan sumber daya manusia yang handal. Sehingga pada akhirnya sumber daya yang dihasilkan oleh pesantren merupakan sumber daya yang mampu memberikan warna ditengah-tengah masyarakat. Sebagai mana tujuan pendidikan pesantren seperti yang dikemukakan oleh Mastuhu, M., (2007) yaitu; menciptakan dan mengembangkan kepribadian muslim, yaitu kepribadian muslim yang beriman dan bertakwa kepada Tuhan, berakhlak mulia, bermanfaat dan berkhidmat kepada masyarakat, mampu berdiri sendiri, bebas dan teguh dalam kepribadian, menyebarkan agama dan menegakkan Islam dan kejayaan umat, mencintai ilmu dalam rangka mengembangkan kepribadian Indonesia.

\section{SIMPULAN}

Demokrasi secara etimologis adalah pemerintahan atau kekuasaan berada ditangan rakyat, sedangkan demokrasi secara terminologis adalah demokrasi menurut pengertian para ahli. Demokrasi tidak hanya merupakan bentuk pemerintahan tetapi juga pola sikap dan budaya suatu masyarakat. Budaya demokrasi berisi nilainilai demokrasi yang dimiliki, dikembangkan, dan dipraktikan oleh masyarakat. Masyarakat yang berbudaya demokrasi atau masyarakat demokratis akan mendukung pemerintahan demokrasi. Budaya demokrasi perlu dipraktikan dalam berbagai kehidupan bernegara.

Pendidikan demokrasi hendaknya dikenalkan di lembaga pendidikan pesantren, karena lembaga pesantren merupakan suatu lembaga pendidikan yang melakukan proses mengembangkan potensi peserta didik (santri) berupa pengetahuan, kesadaran, sikap, keterampilan dan kemauan, serta kemampuan untuk berpartisipasi dalam proses politik. Demokrasi lingkupnya tidak hanya dalam 
negara maupun masyarakat, bahkan di pesantren hendaknya demokrasi dikenalkan terhadap santri.

Untuk mengembangkan civic disposition santri, proses pendidikkan yang dilakukan di pesantren dengan berbagai cara yaitu; 1)

\section{DAFTAR RUJUKAN}

Darmawan, C. 2015. Demokrasi dalam persimpangan makna. Artikel dalam prosiding seminar nasional penguatan komitmen akademik dalam memperkokoh jati diri pkn. ISBN 978-602-8418-27-0.

Dhofier, Z. 1982. Tradisi Pesantren. Jakarta: LP3ES.

Mastuhu, M. 2007. Sistem Pendidikan Nasional Visioner. Jakarta: Lentera Hati.

Sugiyono. 2010. Metodologi Penelitian Pendidikan Pendekatan Kualitatif, Kuantitatif $R \boldsymbol{R} \boldsymbol{D}$. Bandung: Afabeta

Sukmadinata. 2006. Metode Penelitian Kualitatif. Bandung : Graha Aksara keteladanan; 2) latihan dan pembiasaan; 3) mendidik melalui ibrah (mengambil pelajaran); 4) mendidik melalui mauidzah (nasehat); 5) mendidik melalui disiplin; dan 6) mendidik targib wa tahzid (bujukan dan ancaman).

Sundawa, D. 2011. Membangun Kecerdasan Berdemokrasi Warga Negara Muda Melalui Perwujudan Kelas Pendidikan Kewarganegaraan Sebagai Laboratorium Demokrasi. Disertasi. Doktor pada Prodi SPs PKn UPIBandung, Koleksi Tesis Perpustakaan UPI.

Winataputra,U.S dan Budimansyah D. 2012. Pendidikan Kewarganegaraan Dalam Perspektif Internasional, Konteks, Teori dan Profil Pembelajaran. Bandung : Widya Aksara Press

Zamroni. 2011. Pendidikan Demokrasi pada Masyarakat Multikultural. Yogyakarta: Gavin Kalam Utama. 